\title{
Permanent pacing in patients with tricuspid valve replacements
}

\author{
John P Cooper, Subhashini R Jayawickreme, R Howard Swanton
}

\begin{abstract}
Objective-To assess the incidence and complications of permanent pacing in patients who undergo tricuspid valve replacement.

Design-A retrospective study of records of patients who had a tricuspid valve replacement between 1978 and 1993 at the Middlesex hospital.

Results -45 patients with tricuspid valve replacements were followed up for a total of 104 patient years. Ten patients $(22 \%)$ required permanent pacing, five with epicardial leads and five with endocardial. Endocardial leads had significantly lower initial implantation thresholds and were associated with fewer complications.

Conclusion-Patients undergoing tricuspid valve replacement frequently require permanent pacing. Endocardial or epicardial lead insertion should be considered at the time of tricuspid valve replacement.
\end{abstract}

(Br Heart f 1995;73:169-172)

Keywords: permanent pacing; tricuspid valve replacement; pacemaker

There is no ideal method for permanent pacing in a patient with a mechanical prosthetic tricuspid valve. An epicardial permanent pacemaker is frequently used but its insertion is a major operation in patients who are often frail from previous heart surgery. Furthermore, pacing problems and physical complications are more common than with endocardial systems. We identified the proportion of patients undergoing tricuspid valve replacement who required a permanent pacemaker, and the complications following its insertion.

Department of Cardiology, UCL Hospitals, London J P Cooper

S R Jayawickreme R H Swanton

Correspondence to: Dr John P Cooper, Department of Cardiology, UCL Hospitals, Mortimer Street, London W1N 8AA.

Accepted for publication 27 July 1994

\section{Patients and methods}

We performed a retrospective study of 45 patients who underwent tricuspid valve replacement at the Middlesex hospital fied from the operation registry and their hospital records analysed. If the patients had not been reviewed in the past 2 years their general practitioners and/or the patients were contacted directly to confirm that they were still alive and no pacemaker had been inserted. between 1978 and 1993. Patients were identi-

\section{Results}

Forty five patients ( 11 male, 34 female) who underwent tricuspid valve replacement were followed up for a total follow up time after initial valve replacement of 104 patient years (mean (range) 28 (0-180) months, table 1). Thirty four Starr-Edwards and 11 bioprosthetic valves were inserted.

\section{PATIENTS REQUIRING PERMANENT}

\section{PACEMAKERS}

Ten patients $(22 \%)$ required permanent pacing a mean (SEM) of $10 \cdot 1(4 \cdot 0)$ months after tricuspid valve replacement. One permanent pacemaker was therefore inserted for every 10.4 years of patient follow up. All patients who required permanent pacing had complete heart block, atrial fibrillation with slow ventricular response, or sick sinus syndrome with periods of atrial fibrillation (table 2). Atrial pacing was therefore not performed. Five epicardial and five endocardial systems were inserted. One endocardial system was inserted at the time of Starr-Edwards tricuspid valve replacement through the tricuspid annulus, two were inserted 1 and 16 months after tricuspid valve replacement through StarrEdwards valves, and two 1 and 46 months after tricuspid valve replacement through bioprosthetic valves. One epicardial system was inserted at the time of second (StarrEdwards) tricuspid valve replacement 31 months after the initial tricuspid valve replacement, and four were inserted 15,16 , 20 and 32 months after initial tricuspid valve replacement with Starr-Edwards valves.

\section{COMPLICATIONS OF PERMANENT PACING \\ Epicardial leads}

Epicardial leads had higher initial thresholds (mean (SEM) 1.64 $(0.42) \mathrm{V}$ ) than endocardial leads $(0.64(0.12)$ V) $(P<0.05$, MannWhitney test), and epicardial systems had more pacing problems subsequently; one patient (number 3) had three further operations related to the pacemaker, two because of the box migrating and one because of the box failing to pace and sense despite maximal sensitivity and output. Another patient (number 5) required surgical correction because of failure to pace despite maximal output but was considered too frail for this procedure and when last reviewed had experienced no major syncopal episodes. 
Table 1 Summary of details of patients undergoing tricuspid valve replacement

\begin{tabular}{|c|c|c|c|}
\hline & $\begin{array}{l}\text { No pacemaker } \\
(n=35)\end{array}$ & $\begin{array}{l}\text { Pacemaker } \\
(n=10)\end{array}$ & $\begin{array}{l}\text { All patients } \\
(n=45)\end{array}$ \\
\hline Mean (SEM) age at TVR & $59(1 \cdot 8)$ & $64 \cdot 1(2 \cdot 3)$ & $60 \cdot 4(1 \cdot 5)$ \\
\hline $\begin{array}{l}\text { Type of tricuspid valve replacement } \\
\text { Starr-Edwards } \\
\text { Carpentier-Edwards } \\
\text { Ionescu-Shiley }\end{array}$ & $\begin{array}{c}26(74 \cdot 3) \\
8(22 \cdot 8) \\
1(2 \cdot 8)\end{array}$ & $\begin{array}{l}8(80 \cdot 0) \\
1(10 \cdot 0) \\
1(10 \cdot 0)\end{array}$ & $\begin{array}{c}34(75 \cdot 6) \\
9(20 \cdot 0) \\
2(4 \cdot 4)\end{array}$ \\
\hline $\begin{array}{l}\text { Associated valve repacements } \\
\text { None } \\
\text { Mitral } \\
\text { Aortic } \\
\text { Aortic and mitral }\end{array}$ & $\begin{array}{l}2(5 \cdot 7) \\
28(80 \cdot 0) \\
0 \\
5(14 \cdot 3)\end{array}$ & $\begin{array}{l}1(10.0) \\
8(80.0) \\
0 \\
1(10 \cdot 0)\end{array}$ & $\begin{array}{l}3(6 \cdot 7) \\
36(80 \cdot 0) \\
0 \\
6(13 \cdot 3)\end{array}$ \\
\hline Mean (SEM) no of open heart operations & $1 \cdot 7(0 \cdot 1)$ & $1 \cdot 7(0 \cdot 2)$ & $1 \cdot 7(0 \cdot 1)$ \\
\hline $\begin{array}{l}\text { Aetiology } \\
\text { Rheumatic heart disease } \\
\text { Ischaemic heart disease } \\
\text { Congenital heart disease } \\
\text { Dilated cardiomyopathy }\end{array}$ & $\begin{array}{l}32(91 \cdot 4) \\
0 \\
2(5 \cdot 7) \\
1(2 \cdot 8)\end{array}$ & $\begin{array}{l}9^{\star}(90 \cdot 0) \\
1(10 \cdot 0) \\
0 \\
0\end{array}$ & $\begin{array}{l}41(91 \cdot 1) \\
1(2 \cdot 2) \\
2(4 \cdot 4) \\
1(2 \cdot 2)\end{array}$ \\
\hline $\begin{array}{l}\text { Mean (SEM) follow up time after } \\
\text { tricuspid valve replacement (months) }\end{array}$ & $29 \cdot 6(7 \cdot 5)$ & $21 \cdot 4(4 \cdot 6)$ & $27 \cdot 8(6 \cdot 0)$ \\
\hline
\end{tabular}

Values in parentheses are percentages. * One patient with a Starr-Edwards tricuspid valve replacement developed endocarditis before a second tricuspid valve replacement. The patient was electively paced at reoperation.

\section{Endocardial leads}

Although tricuspid regurgitation was not a clinical problem in those patients with endocardial pacing through bioprosthetic valves, it was in the two with endocardial leads across their Starr-Edwards valves. One of these patients (number 6) was terminally ill with heart failure secondary to ischaemic heart disease and chronic renal failure, and developed complete heart block with periods of asystole. The patient was considered unfit for an epicardial pacemaker and died 4 months after endocardial lead insertion from renal failure (fig 1). Necropsy showed the wire to be intact in the right ventricular outflow tract with no trauma to the wire at the site that it crossed the valve (fig 2(A) and (B)). The second patient (number 7) developed episodes of presyncope and a slow ventricular escape rhythm immediately following Starr-Edwards mitral and tricuspid valve replacements. The patient had undergone tricuspid and mitral bioprosthetic valve replacements 13 years previously and was considered too ill for an epicardial pacing system. Endocardial pacing was successful but resulted in mild tricuspid regurgitation. Both patients with endocardial pacemakers across their Starr-Edwards valves required reprogramming of their pacemakers because of an acute rise in threshold (number 6) and a reduction in sensitivity (number 7), which may partly reflect the difficulty in placing the lead in an optimal position mainly because the struts of the Starr-Edwards valve limited our ability to steer the pacing lead. We chose to use a Medtronic 4058 IS 1 bipolar screw-in lead which is robust and less likely to fracture than unipolar leads, although bipolar leads are bigger and thus more likely to cause tricuspid regurgitation.

The need for pacing was not significantly associated with the patient's age at the time of tricuspid valve replacement, the type of associated valve replacement - that is, mitral, aortic, both or neither, the mean number of previous open heart operations, or the type of tricuspid valve replacement (table 1 ).

\section{Discussion}

Little is known about the requirements for permanent pacing in patients undergoing tricuspid valve replacement, although valve surgery, in particular tricuspid valve replacement, is a preoperative risk factor for such pacing. ${ }^{1}$ We found that almost one quarter of patients with tricuspid valve replacements required permanent pacing. This high incidence may reflect the frequent use of StarrEdwards valves at this hospital, although we found no increase in the need for pacing in patients with Starr-Edwards valves compared with those who had bioprostheses.

In view of the high incidence of pacing it is important to consider the optimal method of

Table 2 Details of patients undergoing insertion of a permanent pacemaker

\begin{tabular}{|c|c|c|c|c|c|c|c|}
\hline Patient no & $\begin{array}{l}\text { Age at } \\
\text { tricuspid } \\
\text { valve } \\
\text { replacement } \\
\text { (years) }\end{array}$ & $\begin{array}{l}\text { Type of tricuspid } \\
\text { valve replacement }\end{array}$ & Associated valve & $\begin{array}{l}\text { No of } \\
\text { open } \\
\text { heart } \\
\text { operation }\end{array}$ & Underlying condition & Permanent pacemaker & Indication \\
\hline \multicolumn{8}{|c|}{ Epicardial systems } \\
\hline 1 & 74 & Starr-Edwards & Mitral & 1 & Rheumatic heart disease & $\begin{array}{l}\text { Epicardial pacemaker implanted } \\
\text { subsequent to operation }\end{array}$ & Sick sinus syndrome \\
\hline 2 & 61 & Starr-Edwards & Mitral & 2 & Rheumatic heart disease & $\begin{array}{l}\text { Epicardial pacemaker implanted } \\
\text { subsequent to operation }\end{array}$ & Sick sinus syndrome \\
\hline 3 & 64 & Starr-Edwards & Mitral & 1 & Rheumatic heart disease & $\begin{array}{l}\text { Epicardial pacemaker implanted } \\
\text { subsequent to operation }\end{array}$ & Complete heart block $\frac{0}{\frac{1}{\Phi}}$ \\
\hline 4 & 72 & Starr-Edwards & Aortic and mitral & 2 & Rheumatic heart disease & $\begin{array}{l}\text { Epicardial pacemaker implanted } \\
\text { subsequent to operation }\end{array}$ & $\begin{array}{l}\text { Atrial fibrillation and sle } \\
\text { ventricular response }\end{array}$ \\
\hline 5 & 62 & Starr-Edwards & Mitral & 2 & Rheumatic heart disease/IE & $\begin{array}{l}\text { Epicardial pacemaker at the time } \\
\text { of operation }\end{array}$ & $\begin{array}{l}\text { Atrial fibrillation and slo } \\
\text { ventricular response }\end{array}$ \\
\hline \multicolumn{8}{|c|}{ Endocardial systems } \\
\hline 6 & 62 & Starr-Edwards & None & 3 & Ischaemic heart disease & $\begin{array}{l}\text { Endocardial pacemaker implanted } \\
\text { subsequent to operation }\end{array}$ & Complete heart block $₫$ \\
\hline 7 & 71 & Starr-Edwards* & Mitral & 2 & Rheumatic heart disease & $\begin{array}{l}\text { Endocardial pacemaker implanted } \\
\text { subsequent to operation }\end{array}$ & Complete heart block $\underset{乛}{0}$ \\
\hline 8 & 50 & Starr-Edwards & Mitral & 1 & Rheumatic heart disease & $\begin{array}{l}\text { Endocardial pacemaker at the time } \\
\text { of operation }\end{array}$ & $\begin{array}{l}\text { Atrial fibrillation and slö } \\
\text { ventricular response }\end{array}$ \\
\hline 9 & 68 & Ionescu-Shiley & Mitral & 1 & Rheumatic heart disease & $\begin{array}{l}\text { Endocardial pacemaker implanted } \\
\text { subsequent to operation }\end{array}$ & $\begin{array}{l}\text { Atrial fibrillation and slo․ } \\
\text { ventricular response을 }\end{array}$ \\
\hline 10 & 57 & Carpentier-Edwards & Mitral & 2 & Rheumatic heart disease & $\begin{array}{l}\text { Endocardial pacemaker } \\
\text { implanted subsequent to operation }\end{array}$ & Sick sinus syndrome \\
\hline
\end{tabular}

*This patient who underwent a Carpentier-Edwards tricuspid valve replacement 13 years earlier had complete heart block after insertion of a Starr-Edwards prosthesis permanent pacing and follow up data therefore relate to the Starr-Edwards valve. IE, infective endocarditis. 
Figure $1 X$-ray taken in the right anterior oblique projection of patient number 6 demonstrating the endocardial wire crossing the Starr-Edwards tricuspid valve and its insertion into the right ventricular outflow tract.

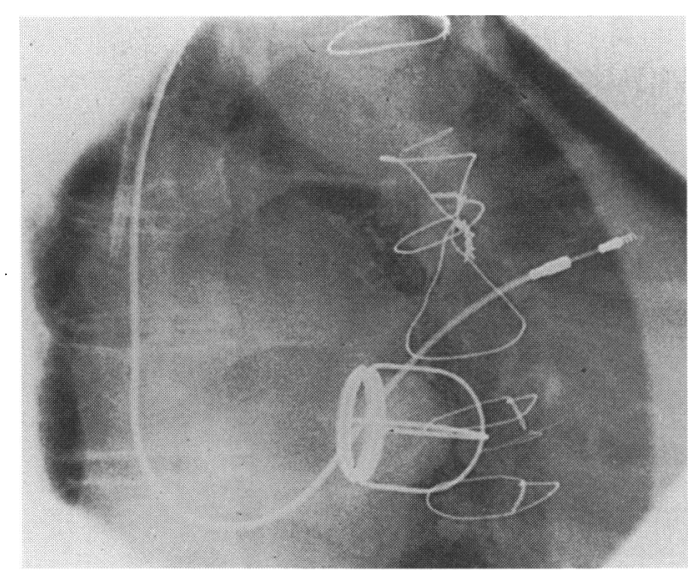

pacing in these patients. Placement of a tricuspid prosthesis has previously been considered an absolute contraindication to performing transvenous pacing. Epicardial pacing systems have therefore been used but these require a second major operation which involves careful dissection of adhesions from the ventricular surface in patients who are often frail. For this reason some have advocated placing permanent epicardial leads at the time of initial operation which if required can be connected to a pacemaker under local anaesthesia. ${ }^{2}$ Our study suggests that most patients $(70 \%)$ require permanent pacing for more than one year after tricuspid valve replacement, although others have reported that such pacing after tricuspid surgery was more common in the immediate postoperative period (13 of 14 patients were paced for a mean of $11(4.5)$ days after operation. ${ }^{3}$

Our study demonstrates that epicardial pacing is associated with increased problems related to both poor pacing thresholds at the time of implant and subsequent local complications of abdominal pacemakers and wires. If a patient does not have atrial fibrillation and has no evidence of heart block, endocardial atrial pacing may be adequate and avoids the need for pacing across the tricuspid valve. However, in all our 10 cases ventricular pacing was desirable or necessary. Problems with epicardial pacing may be overcome by an endocardial lead sewn outside the tricuspid valve annulus inserted at the time of replacement ${ }^{4}$; this procedure was performed in one of our patients (number 8). Clearly this can be employed only if it is obvious that the patient requires permanent pacing at the time of operation. Others have suggested pacing with a transvenous wire via the coronary sinus into the middle cardiac or posterior left ventricular veins. ${ }^{5}$ The pacing thresholds achieved are high in this position and there is a theoretical risk of thrombosis of the coronary sinus, although this has not been observed in a limited number of postmortem examinations of patients paced in this way. ${ }^{5}$

Recently it has become apparent that pacing across bioprostheses is possible and the limited reports of its use indicate that the short and long term pacing characteristics are similar to normal; endocardial leads were placed in 14 patients after tricuspid surgery and no acute or chronic pacing or sensing problems were noted after a mean follow up of 30.6 months. ${ }^{3}$ Endocardial pacing across a bioprosthesis is associated with the development of mild haemodynamically insignificant tricuspid regurgitation ${ }^{67}$ but has not been reported to reduce the longevity of the valve; indeed a Hancock valve has been reported to be functioning well 8 years after insertion of a pacing wire across the valve. ${ }^{7}$ We have demonstrated that endocardial pacing wires may be successfully inserted across StarrEdwards tricuspid valves. Suitable pacing thresholds are achieved with this procedure although patients develop tricuspid regurgitation. We would not consider endocardial pacing across a disc prosthesis because of the

\begin{tabular}{|c|c|c|c|c|c|c|}
\hline Symptoms & $\begin{array}{l}\text { Months } \\
\text { post } \\
\text { tricuspid } \\
\text { valve } \\
\text { replacement }\end{array}$ & $\begin{array}{l}\text { Threshold } \\
\text { (V) }\end{array}$ & $\begin{array}{l}\text { Sensitivity } \\
(m A)\end{array}$ & Complications & $\begin{array}{l}\text { Follow up post } \\
\text { permanent } \\
\text { pacemaker } \\
\text { (months) }\end{array}$ & $\begin{array}{l}\text { Alive or } \\
\text { dead }\end{array}$ \\
\hline Syncope & 20 & $1 \cdot 4$ & Data not available & Pacing problem correctable by reprogramming pacemaker & 5 & Alive \\
\hline Lethargy & 16 & $3 \cdot 0$ & Data not available & None & 10 & Alive \\
\hline Syncope & 32 & $1 \cdot 1$ & $2 \cdot 0$ & Pacing problem requiring reoperation & 20 & Alive \\
\hline Congestive cardiac failure & 15 & $2 \cdot 1$ & $3 \cdot 1$ & None & 1 & Dead \\
\hline Presyncope & 31 & $0 \cdot 6$ & $2 \cdot 4$ & Pacing problem requiring reoperation & 7 & Alive \\
\hline Syncope & 16 & $0 \cdot 8$ & $1 \cdot 2$ & $\begin{array}{l}\text { Tricuspid regurgitation and pacing problem correctable } \\
\text { by reprogramming pacemaker }\end{array}$ & 4 & Dead \\
\hline Presyncope & 1 & 0.6 & Data not available & $\begin{array}{l}\text { Tricuspid regurgitation and pacing problem correctable } \\
\text { by reprogramming pacemaker }\end{array}$ & 1 & Alive \\
\hline Presyncope & 0 & 0.5 & Data not available & None & 35 & Alive \\
\hline Presyncope & 1 & 0.3 & Data not available & None & 0 & Alive \\
\hline Presyncope & 46 & $1 \cdot 0$ & 2.5 & None & 3 & Alive \\
\hline
\end{tabular}



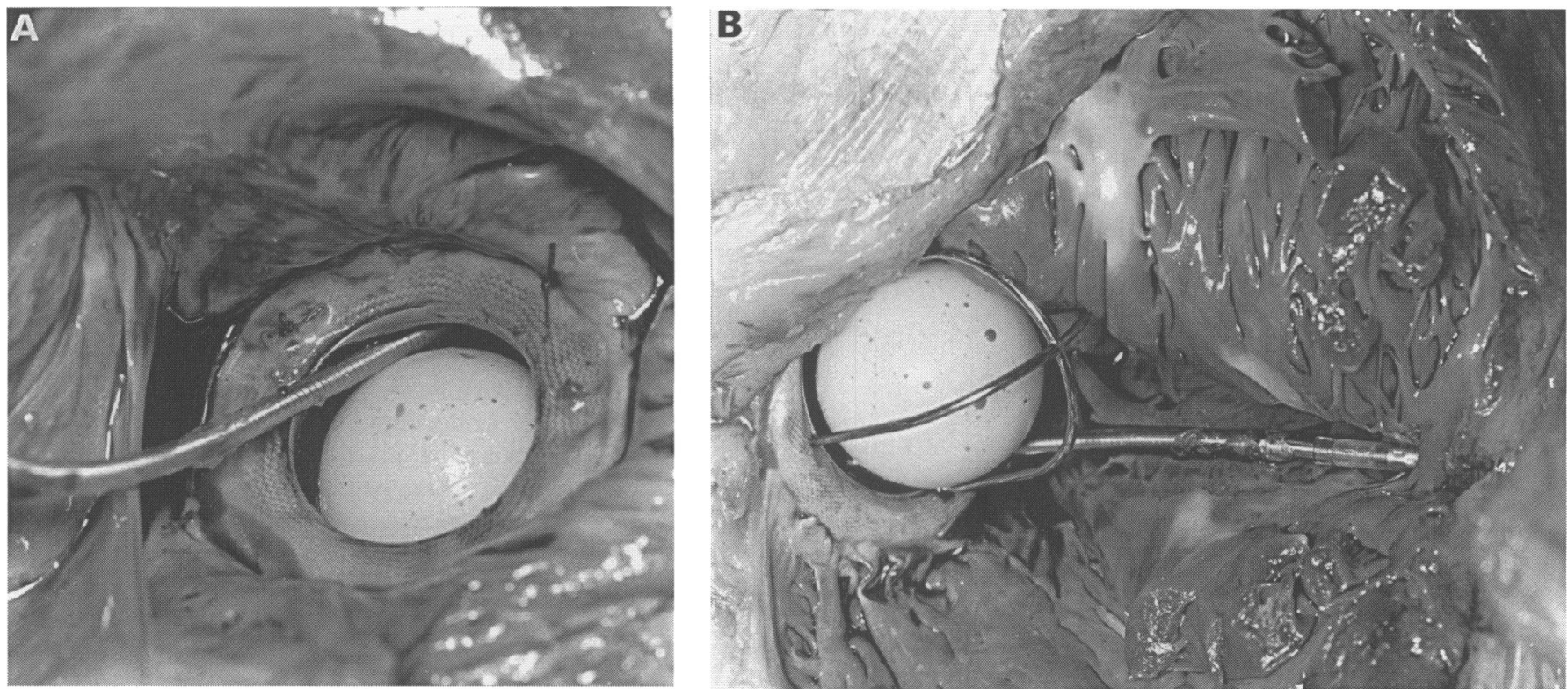

Figure 2 Postmortem specimen of patient number 6 showing the pacing wire and the Starr-Edwards tricuspid prosthesis viewed from $(A)$ the right atrium and $(B)$ the right ventricle. The ball is splinted away from the ring by the pacing wire.

possibility of the disc jamming open resulting in severe tricuspid regurgitation or stenosis.

\section{Conclusion}

In view of the likelihood of patients with mechanical tricuspid valve replacements requiring a permanent pacemaker and the superiority of endocardial systems compared with that of epicardial, we would recommend that:

(a) particular care be taken to identify those who may need a permanent pacemaker before tricuspid valve replacement so that an endocardial system may be inserted at the time of operation;

(b) placing a permanent epicardial pacing wire should be considered at the time of tricuspid valve replacement even if there is no indication for permanent pacing; and

(c) if a patient requires a pacemaker and is too ill for an epicardial system then an endocardial wire can be inserted across a
Starr-Edwards prosthesis as a last resort. If a patient has a bioprosthetic tricuspid valve replacement and requires pacing we would recommend insertion of an active fixation endocardial lead.

We are grateful to Eileen Firman for her help in contacting patients.

1 Goldman B. Pacing and open heart surgery [abstract 135/871]. PACE 1988;11:823.

2 Gaillard D, Lespinasse $P$, Vanetti A. Cardiac pacing and valvular surgery. $P A C E$ 1988;11:2142-8.

3 Sorrentino R, Edwards B, Smith B, Wharton J. Endocardial ventricular pacemaker lead placement in patients with tricuspid valve surgery [abstract 326]. PACE 1993;16:931.

4 Hayes D, Zolnick M, Trusty J. Pacemaker placement in patients with tricuspid valve surgery. PACE 1988;11:823.

5 Lee $M$. Special considerations in ventricular pacing in patients with tricuspid valve disease. Ann Thorac Surg 1983;36:89-92.

6 Medeiros P, Kormann D, Pachon J, Albornoz R, Paulista P, Sousa J. Long-term endocardial ventricular pacing through bioprosthetic tricuspid valves [abstract 310]. $P A C E$ 1993;16:1187.

7 Pernenkil R, Wright J. Endocardial pacing through a prosthetic tricuspid valve. $P A C E$ 1990;13:1365-6. 